\title{
ADVANCED CONTROLLER DESIGN FOR ACTIVE BRAKING SYSTEMS
}

\author{
Vu Van Tan \\ University of Transport and communications
}

\begin{abstract}
This paper presents the synthesis of an advanced controller for an active braking system on trucks, by combining the $\mathrm{H}_{\infty}$ method with the Linear Parameter Varying system (LPV). The forward velocity and the normalized load transfer at the rear axle are considered as the two varying parameters. The grid-based LPV approach is used to synthesize the $\mathrm{H}_{\infty} / \mathrm{LPV}$ controller. In order to adapt the active braking system to the risk of the vehicle rollover, the parameter dependent weighting function for the lateral acceleration is used as the most important weighting function. The simulation results in the frequency domain show that the use of the $\mathrm{H}_{\infty} / \mathrm{LPV}$ active brake control system has significantly reduced the transfer function magnitude of the normalized load transfer at the two axles, which demonstrates the effectiveness of the proposed method.
\end{abstract}

Keywords: Intelligent transportation systems; vehicle dynamics; active braking system; roll stability; $H_{\infty}$ control; LPV system

Received: 09/9/2020; Revised: 13/11/2020; Published: 30/11/2020

\section{THIẾT KẾ BỘ ĐIỀU KHIỀN NÂNG CAO CHO HỆ THỐNG PHANH CHỦ ĐỘNG}

Vũ Văn Tấn*

Trưòng Đại học Giao thông Vận tải

\section{TÓM TẮT}

Bài báo này trình bày tổng hợp bộ điều khiển nâng cao cho hệ thống phanh chủ động trên ô tô tải, bằng cách kết hợp phương pháp $\mathrm{H}_{\infty}$ với mô hình hệ thống có thông số thay đổi tuyến tính LPV. Vận tốc chuyển động và hệ số chuyển tải ở cầu sau được xem xét là hai thông số thay đổi. Phương pháp LPV dựa trên cách tiếp cận chia lưới được sử dụng để tổng hợp bộ điều khiển $\mathrm{H}_{\infty} / \mathrm{LPV}$. Để điều chỉnh hệ thống phanh chủ động đáp ứng được với các nguy cơ lật ngang của ô tô, hàm trọng số phụ thuộc vào gia tốc ngang được xem là thông số quan trợng nhất. Kết quả mô phỏng trong miền tần số cho thấy việc sử dụng hệ thống phanh chủ động điều khiển $\mathrm{H}_{\infty} / \mathrm{LPV}$ đã làm giảm đáng kể độ lớn hàm truyền từ góc đánh lái đến hệ số chuyển tải ở hai cầu xe, điều này đã chứng minh hiệu quả của phương pháp đề xuất.

Từ khóa: Hệ thống giao thông thông minh; động lục của xe; hệ thống phanh chủ động; ổn định lật ngang; điều khiến bền vững $H_{\infty}$; hệ thống $L P V$

Ngày nhận bài: 09/9/2020; Ngày hoàn thiện: 13/11/2020; Ngày đăng: 30/11/2020

Email:vvtan@utc.edu.vn

https://doi.org/10.34238/tnu-jst.3572 


\section{Introduction}

Active Braking System (ABS) is the general concept of controlled braking on vehicles, such as Electronic Brake System (EBS), Antilock Braking System (ABS), Advanced Emergency Braking System (AEBS), Autonomous Emergency Braking (AEB) [1], [2]. The active braking system was introduced to the automotive industry in the 1950 s with the goal to improve braking performance. For a long time, hydraulic brake systems dominated the market; however, the main disadvantage is the noticeable oscillation of the wheel slip around a reference value. Today, electromechanical actuators are becoming common and will probably totally replace hydraulic brakes in the near future, along with the development of X-by-wire technology. These actuators allow the application of a smoother and continuous braking action on the brake pads [3]. The evolution of braking systems in the automotive field is well described in Figure 1 [4]. It indicates that, since electronics have been integrated into vehicles, the advances in the development of active vehicle control systems have been inextricably linked to advances in sensors and actuators technology [4]. The effect of the controlled suspension is only to keep the vehicle body perpendicular to the road, since it cannot reduce the lateral tyre force component. Therefore, the role of an active braking system in order to avoid the vehicle rollover situation is very important [5]-[7].

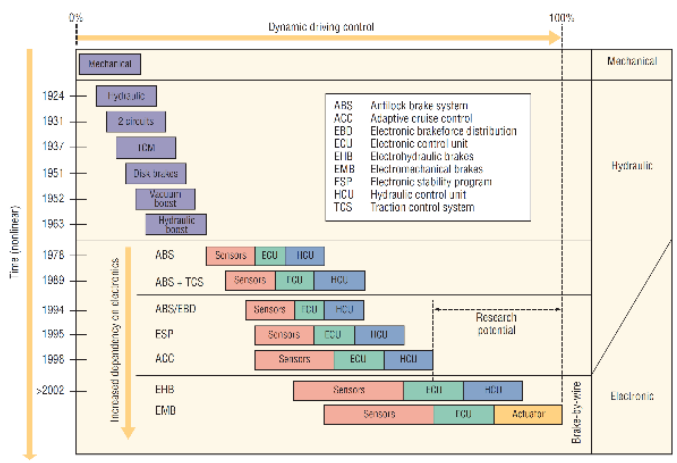

Figure 1. The evolution of braking systems [4]
LPV theory is closely related to gain scheduling via interpolation of point designs. LPV theory provides a mathematically rigorous approach to the design of gain-scheduled controllers. This includes powerful guarantees on the performance and robustness in the presence of time-varying dynamics and uncertainty. The LPV approach is considered in this paper. It is known to be able to handle system nonlinearities by considering them as varying parameters and, as well, to make the controller performance varying through the linear introduction of smart (high-level) parameters in several chapters from the book [4].

In the literature, one can find the following references related to improved roll stability:

- In [8], a combined control structure between the active anti-roll bar system and the active braking system was proposed. The best part of this solution is that, in a normal driving situation, only the active anti-roll bar system is functional and the active braking system is only activated when the vehicle comes close to a rollover situation.

- In [3], a robust control algorithm for an antilock brake system is proposed. The method used is based on the static-state feedback of the longitudinal slip and does not involve controller scheduling with changing vehicle speed or road adhesion coefficient estimation.

Based on the idea in [8], here the authors would like to present preliminary research results on the active braking system with the aim of preventing the vehicle rollover phenomenon. Hence, this paper contributes the following elements:

- The active braking system is designed based on the control signal being the yaw moment control, which is generated by the difference in braking force at four wheels. This allows the controller to be synthesized more easily than when considering the braking force at each wheel.

- The grid-based LPV approach is used to set up an $\mathrm{H}_{\infty} / \mathrm{LPV}$ controller self-scheduled by two varying parameters: the forward velocity and the normalized load transfer of the rear 
axle. The parameter dependent weighting function for the lateral acceleration is used in order to adapt the vehicle performance to the risk of rollover.

The paper is organised as follows: Section 2 presents the yaw-roll model of a truck. Section 3 develops the $\mathrm{H}_{\infty} / \mathrm{LPV}$ control synthesis for an active braking system to prevent rollover. Section 4 introduces the grid-based LPV approach. Section 5 presents some simulation results in the frequency domain. Finally, some conclusions are drawn in section 6 .

\section{Vehicle modelling}

The yaw-roll model of a truck for studying the active anti-roll bar system is presented in [9]. Here, this model is suitably modified for the active braking system by using the yaw moment control $\mathrm{M}_{\mathrm{z}}$ as shown in Figure 2. The variables of the yaw-roll model are detailed in Table 1 . The motion differential equations are formalized as follows:

$$
\left\{\begin{aligned}
& m v(\dot{\beta}+\dot{\psi})-m_{s} h \ddot{\phi}=F_{y f}+F_{y r} \\
&-I_{x z} \ddot{\phi}+I_{z z} \ddot{\psi}=F_{y f} l_{f}-F_{y r} l_{r}+M_{z} \\
&\left(I_{x x}+m_{s} h^{2}\right) \ddot{\phi}-I_{x z} \ddot{\psi}=m_{s} g h \phi+m_{s} v h(\dot{\beta}+\dot{\psi}) \\
& \quad-k_{f}\left(\phi-\phi_{u f}\right)-b_{f}\left(\dot{\phi}-\dot{\phi}_{u f}\right)+M_{A R f} \\
& \quad-k_{r}\left(\phi-\phi_{u r}\right)-b_{r}\left(\dot{\phi}-\dot{\phi}_{u r}\right)+M_{A R r} \\
&-r F_{y f}=m_{u f} v\left(r-h_{u f}\right)(\dot{\beta}+\dot{\psi})+m_{u f} g h_{u f} \phi_{u f}-k_{t f} \phi_{u f f} \\
&+k_{f}\left(\phi-\phi_{u f f}\right)+b_{f}\left(\dot{\phi}-\dot{\phi}_{u f}\right)+M_{A R f} \\
&-r F_{y r}=m_{u r} v\left(r-h_{u r}\right)(\dot{\beta}+\dot{\psi})-m_{u r} g h_{u r} \phi_{u r} r k_{t r} \phi_{u r} \\
&+k_{r}\left(\phi-\phi_{u r}\right)+b_{r}\left(\dot{\phi}-\dot{\phi}_{u r}\right)+M_{A R r}
\end{aligned}\right.
$$

where $F_{y f, r}$ are the lateral tyre forces and $M_{A R f, r}$ the moments of the passive anti-roll bar system impact the unsprung and sprung masses at the two axles [10].
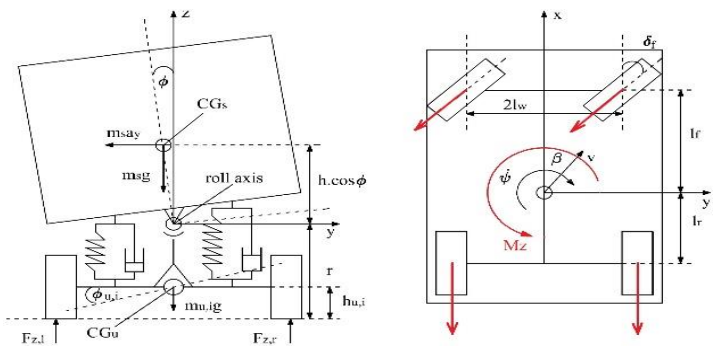

Figure 2. Yaw-Roll model of a truck
The yaw moment control $M_{z}$ generated by the active braking system. In this case, we use an assumption that the driving throttle is constant during a lateral manoeuver and the forward velocity depends only on the brake forces at the four wheels $\left(F_{b}\right)$. The differential equation of the forward velocity is: $m \dot{v}=-4 F_{b}$

The motion differential equations (1)-(2) can be rewritten in the LPV state-space

\begin{tabular}{|c|c|c|c|}
\hline Symbols & Description & Value & Unit \\
\hline$m_{s}$ & Sprung mass & 12487 & $\mathrm{~kg}$ \\
\hline$m_{u, f}$ & $\begin{array}{l}\text { Unsprung mass on the } \\
\text { front axle }\end{array}$ & 706 & $\mathrm{~kg}$ \\
\hline$m_{u, r}$ & $\begin{array}{l}\text { Unsprung mass on the } \\
\text { rear axle }\end{array}$ & 1000 & $\mathrm{~kg}$ \\
\hline$m$ & The total vehicle mass & 14193 & $\mathrm{~kg}$ \\
\hline$v$ & Forward velocity & - & $\mathrm{km} / \mathrm{h}$ \\
\hline$v_{w i}$ & $\begin{array}{l}\text { Components of the } \\
\text { forward velocity }\end{array}$ & - & $\mathrm{km} / \mathrm{h}$ \\
\hline$h$ & $\begin{array}{l}\text { Height of CG of sprung } \\
\text { mass from roll axis }\end{array}$ & 1.15 & $\mathrm{~m}$ \\
\hline$h_{u, i}$ & $\begin{array}{l}\text { Height of CG of unsprung } \\
\text { mass from ground }\end{array}$ & 0.53 & $\mathrm{~m}$ \\
\hline$r$ & $\begin{array}{l}\text { Height of roll axis from } \\
\text { ground }\end{array}$ & 0.83 & $\mathrm{~m}$ \\
\hline$a_{y}$ & Lateral acceleration & - & $\mathrm{m} / \mathrm{s}^{2}$ \\
\hline$\beta$ & $\begin{array}{l}\text { Side-slip angle at center } \\
\text { of mass }\end{array}$ & - & $\mathrm{rad}$ \\
\hline$\psi$ & Heading angle & - & $\mathrm{rad}$ \\
\hline$\dot{\psi}$ & Yaw rate & - & $\mathrm{rad} / \mathrm{s}$ \\
\hline$\alpha$ & Side slip angle & - & $\mathrm{rad}$ \\
\hline$\phi$ & Sprung mass roll angle & - & $\mathrm{rad}$ \\
\hline$\phi_{u, i}$ & Unsprung mass roll angle & - & $\mathrm{rad}$ \\
\hline$\delta_{f}$ & Steering angle & - & $\mathrm{rad}$ \\
\hline$C_{f}$ & $\begin{array}{l}\text { Tire cornering stiffness } \\
\text { on the front axle }\end{array}$ & 582 & $\mathrm{kN} / \mathrm{rad}$ \\
\hline$C_{r}$ & $\begin{array}{l}\text { Tire cornering stiffness } \\
\text { on the rear axle }\end{array}$ & 783 & $\mathrm{kN} / \mathrm{rad}$ \\
\hline
\end{tabular}
representation with the forward velocity as the varying parameter $\left(\rho_{l}=v\right)$ as follows:

$$
\dot{X}=A\left(\rho_{1}\right) \cdot X+B_{1}\left(\rho_{1}\right) \cdot \mathrm{W}+B_{2}\left(\rho_{1}\right) \cdot U
$$

with the state vector $X=\left[\beta \dot{\psi} \phi \dot{\phi} \phi_{u f} \phi_{u r} \rho_{1}\right]^{T}$, the exogenous disturbance $w=\left[\delta_{f}\right]^{T}$ and the control input $u=\left[M_{Z}\right]^{T}$.

Table 1. Variables and Parameters of the yaw-roll model 


\begin{tabular}{clcl}
\hline Symbols & \multicolumn{1}{c}{ Description } & Value & \multicolumn{1}{c}{ Unit } \\
\hline$k_{f}$ & $\begin{array}{l}\text { Suspension roll stiffness } \\
\text { on the front axle }\end{array}$ & 380 & $\begin{array}{l}\mathrm{kNm} / \mathrm{r} \\
\mathrm{ad}\end{array}$ \\
\hline$k_{r}$ & $\begin{array}{l}\text { Suspension roll stiffness } \\
\text { on the rear axle }\end{array}$ & 684 & $\begin{array}{l}\mathrm{kNm} / \mathrm{r} \\
\mathrm{ad}\end{array}$ \\
\hline$b_{f}$ & $\begin{array}{l}\text { Suspension roll damping } \\
\text { on the front axle }\end{array}$ & 100 & $\mathrm{kN} / \mathrm{rad}$ \\
\hline$b_{r}$ & $\begin{array}{l}\text { Suspension roll damping } \\
\text { on the rear axle }\end{array}$ & 100 & $\mathrm{kN} / \mathrm{rad}$ \\
\hline$k_{t f}$ & $\begin{array}{l}\text { Tire roll stiffness on the } \\
\text { front axle }\end{array}$ & 2060 & $\begin{array}{l}\mathrm{kNm} / \mathrm{r} \\
\mathrm{ad}\end{array}$ \\
\hline$k_{t r}$ & $\begin{array}{l}\text { Tire roll stiffness on the } \\
\text { rear axle }\end{array}$ & 3337 & $\begin{array}{l}\mathrm{kNm} / \mathrm{r} \\
\mathrm{ad}\end{array}$ \\
\hline$I_{x x}$ & $\begin{array}{l}\text { Roll moment of inertia } \\
\text { of sprung mass }\end{array}$ & 24201 & $\mathrm{kgm}{ }^{2}$ \\
\hline$I_{x z}$ & $\begin{array}{l}\text { Yaw-roll product of } \\
\text { inertial of sprung mass }\end{array}$ & 4200 & $\mathrm{kgm}{ }^{2}$ \\
\hline$I_{z z}$ & $\begin{array}{l}\text { Yaw moment of inertia } \\
\text { of sprung mass }\end{array}$ & 34917 & $\mathrm{kgm}{ }^{2}$ \\
\hline$l_{f}$ & $\begin{array}{l}\text { Length of the front axle } \\
\text { from the CG }\end{array}$ & 1.95 & $\mathrm{~m}$ \\
\hline$l_{r}$ & $\begin{array}{l}\text { Length of the rear axle } \\
\text { from the CG }\end{array}$ & 1.54 & $\mathrm{~m}$ \\
\hline$l_{w}$ & $\begin{array}{l}\text { Half of the vehicle width } \\
\mu\end{array}$ & $\begin{array}{l}\text { Road adhesion coefficient } \\
1\end{array}$ & $\mathrm{~m}$ \\
\hline
\end{tabular}

3. The $H_{\curvearrowright} / L P V$ controller synthesis for an active braking system

\subsection{The $H_{\circ} / L P V$ control design}

In this section, the $\mathrm{H}_{\infty} / \mathrm{LPV}$ control design is presented for the active braking system in heavy vehicles to prevent rollover in emergency situations. In Figure 3, the $\mathrm{H}_{o} / \mathrm{LPV}$ control structure includes the nominal model $G\left(\rho_{1}\right)$, the controller $K\left(\rho_{1}, \rho_{2}\right)$, the performance output $Z$, the control input $U$, the measured output $Y$, and the measurement noise $n . \delta_{f}$ is the steering angle (disturbance signal), set by the driver. The measured output is $Y=\left[a_{y}, \dot{\phi}\right]$. The input scaling weight $W_{\delta}$, chosen as $W_{\delta}=0.02$. The weighting functions $W_{n 1}$ and $W_{n 2}$ are selected as: $W_{n 1}=W_{n 2}=0.02$, which accounts for small sensor noise models in the control design.

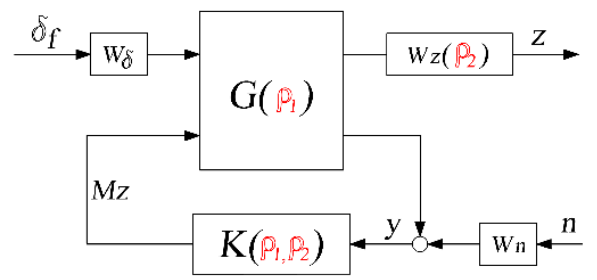

Figure 3. Closed-loop of the active braking system
The parameter dependent weighting function $W_{z}$ represents the performance output and is chosen as

$W_{z}=\operatorname{diag}\left[\frac{\tau_{1} s+\tau_{2}}{\tau_{3} s+\tau_{4}}, \rho_{2} \frac{\zeta_{1} s^{2}+\zeta_{2} s+\zeta_{3}}{\zeta_{4} s^{2}+\zeta_{5} s+\zeta_{6}}\right]$.

The purpose of this weighting function is to keep the yaw moment $M_{z}$ and the lateral acceleration $a_{y}$ as small as possible over the desired frequency range to over $4 \mathrm{rad} / \mathrm{s}$, which represents the limited bandwidth of the driver [8], [11]. The varying parameter is defined as $\rho_{2}=f(|R r|)$.

\subsection{The solution of the $H_{d} / L P V$ control problem}

According to Figure 3, the concatenation of the nonlinear model (3) with the performance weighting functions has a partitioned representation in the following form:

$$
\left[\begin{array}{l}
\dot{X}(t) \\
Z(t) \\
Y(t)
\end{array}\right]=\left[\begin{array}{lll}
A(\rho) & B_{1}(\rho) & B_{2}(\rho) \\
C_{1}(\rho) & D_{11}(\rho) & D_{12}(\rho) \\
C_{2}(\rho) & D_{21}(\rho) & D_{22}(\rho)
\end{array}\right]\left[\begin{array}{c}
X(t) \\
\mathrm{W}(t) \\
U(t)
\end{array}\right]
$$

where the exogenous input $W(t)=\left[\delta_{f}, n\right]$, the control input $U(t)=\left[M_{z}\right]$, the measured output vector $Y=\left[a_{y}, \dot{\phi}\right]$ and the performance output vector $Z(t)=\left[M_{z} a_{y}\right]^{T}$.

The LPV model of the active braking system (4) uses the varying parameters $\rho=\left[\rho_{1} ; \rho_{2}\right]$, which are known in real time. The parameter $\rho_{1}=v$ is measured directly, while the parameter $\rho_{2}=f(|R r|)$ can be calculated by using the measured roll angle of the unsprung mass at the rear axle $\phi_{u r}$.

\section{The grid-based LPV approach}

The LPV system in the equation (3) is conceptually represented by a state-space system $S(\rho)$ that depends on a time varying parameter vector $\rho \in P_{\rho}$. A grid-based LPV model of this system is a collection of linearizations on a gridded domain of parameter values [12]. For general LPV systems, this conceptual representation requires storing the state-space system at an infinite number of points in the domain of $\rho$. For each grid point $\hat{\rho}_{k}$, there is a 
corresponding LTI system $\left(A\left(\hat{\rho}_{k}\right), B\left(\hat{\rho}_{k}\right), C\left(\hat{\rho}_{k}\right), D\left(\hat{\rho}_{k}\right)\right)$ which describes the dynamics of $S\left(\hat{\rho}_{k}\right)$ when $\hat{\rho}_{k}$ is held constant. It is worth noting that $\hat{\rho}_{k}$ represents a constant vector corresponding to the $k^{\text {th }}$ grid point, while $\rho_{i}$ is later used to denote the $i^{\text {th }}$ element of the vector $\rho$. All the linearized systems on the grid have identical inputs $u$, outputs $y$ and state vectors $x$. Together they form an LPV system approximation of $S(\rho)$ [13], [14].

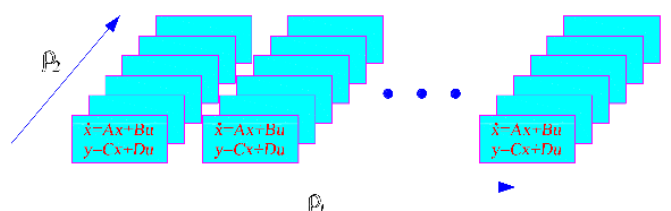

Figure 4. $L P V$ models defined on a rectangular grid

The grid-based LPV approach is pictorially represented in Figure 4, with the example of such a system that depends on two parameters $\left(\rho_{1}, \rho_{2}\right)$. The grid-based LPV approach approximates this conceptual representation by storing the LPV system as a state-space array defined on a finite, gridded domain. In this paper, we use the grid-based LPV approach and the LPVTools ${ }^{\mathrm{TM}}$ presented in [15], [16] to synthesize the $\mathrm{H}_{\circ} / \mathrm{LPV}$ active braking control system. It requires a gridded parameter space for the two varying parameters $\rho=\left[\rho_{1}, \rho_{2}\right]$.

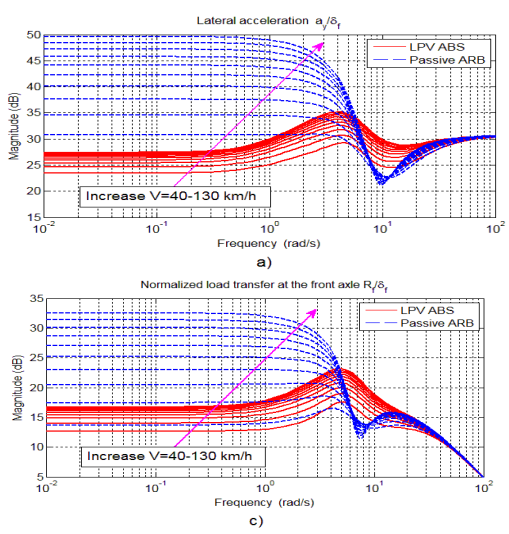

The $\mathrm{H}_{\infty}$ controllers are synthesized for 10 grid points of the forward velocity in the range $\rho_{l}=v=[40 \mathrm{~km} / \mathrm{h} ; 130 \mathrm{~km} / \mathrm{h}]$ and 5 grid points of the normalized load transfer at the rear axle in a range $\rho_{2}=f(|R r|)=[0 ; 1]$. The grid points and the LPV controller synthesis using LPVTools ${ }^{\mathrm{TM}}$ are expressed by the following commands:

rhol

pgrid('rhol','linspace(40/3.6,130/3.6,10));

rho2 $=$ pgrid $($ 'rho2', linspace $(0,1,5))$;

[Klpv,normlpv] $=$ lpvsyn (H,nmeas,ncont).

\section{Simulation results analysis}

The parameters of the yaw-roll model of a truck are detailed in Table 1. To evaluate the effectiveness of the active braking system on the prevention of vehicle rollover in the frequency domain, the two following cases will be considered as:

- $\mathbf{1}^{\text {st }}$ case: the varying parameters $\rho_{1}=v$ varies from $40 \mathrm{~km} / \mathrm{h}$ to $130 \mathrm{~km} / \mathrm{h}$ and $\rho_{2}=0.8$;

- $2^{\text {nd }}$ case: the varying parameters $\rho_{2}=[0,0.8$, 1] varies and $\rho_{l}=v=80 \mathrm{~km} / \mathrm{h}$.

5.1. $1^{\text {st }}$ case: the varying parameters $\rho_{1}=v$ varies from $40 \mathrm{~km} / \mathrm{h}$ to $130 \mathrm{~km} / \mathrm{h}$ and $\rho_{2}=0.8$

Vehicle rollover often occurs when the forward velocity is higher than $60 \mathrm{~km} / \mathrm{h}$. Therefore, in this case, the author considers the varying parameter of the forward velocity $\rho_{l}=v$ from $40 \mathrm{~km} / \mathrm{h}$ to $130 \mathrm{~km} / \mathrm{h}$, while the varying parameter $\rho_{2}$ is kept constant at 0.8 .
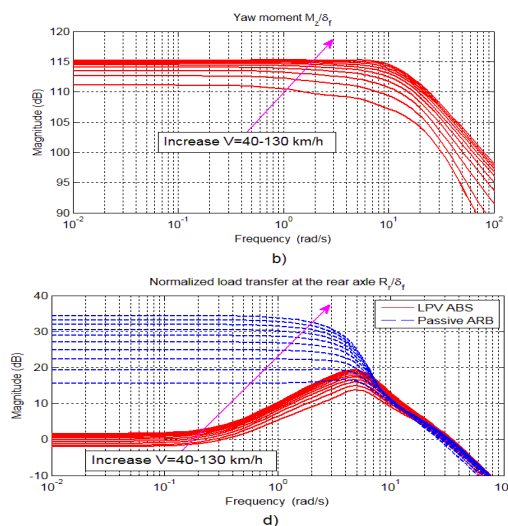

Figure 5. The $1^{\text {st }}$ case: transfer function magnitude of $(a)$ the lateral acceleration $\frac{a_{y}}{\delta_{f}},(b)$ the yaw moment $\frac{M_{Z}}{\delta_{f}},(c, d)$ the normalized load transfers $\frac{R_{f, r}}{\delta_{f}}$ at the two axles 


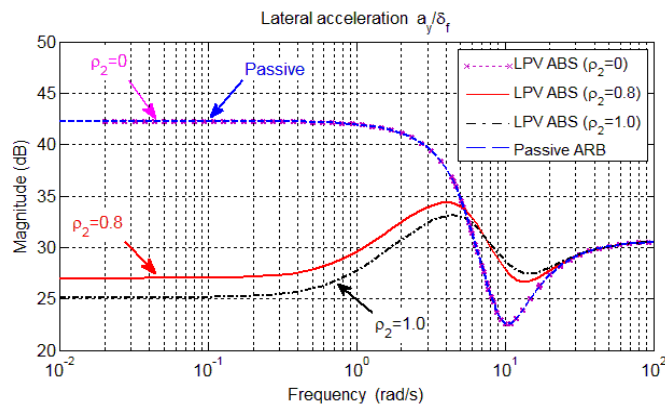

a)

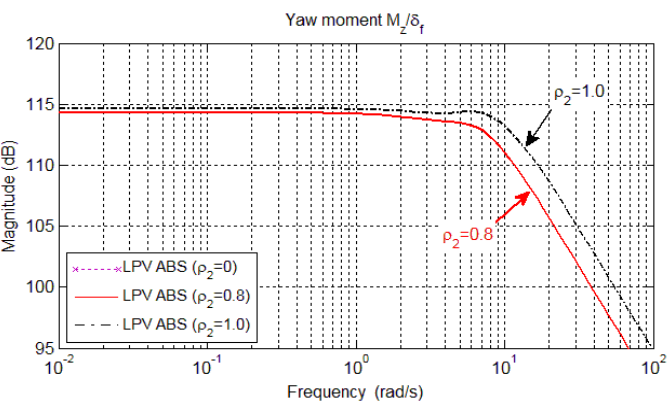

b)

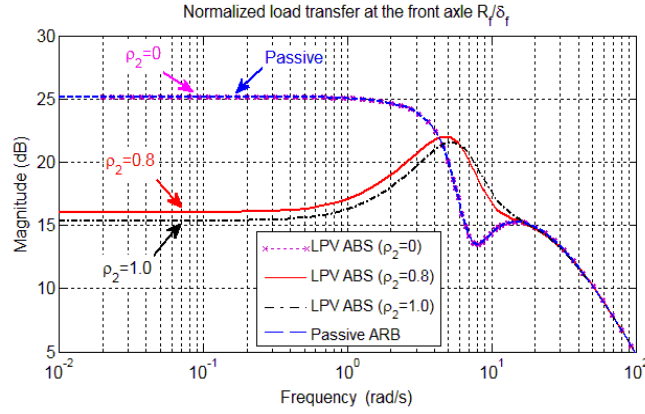

c)

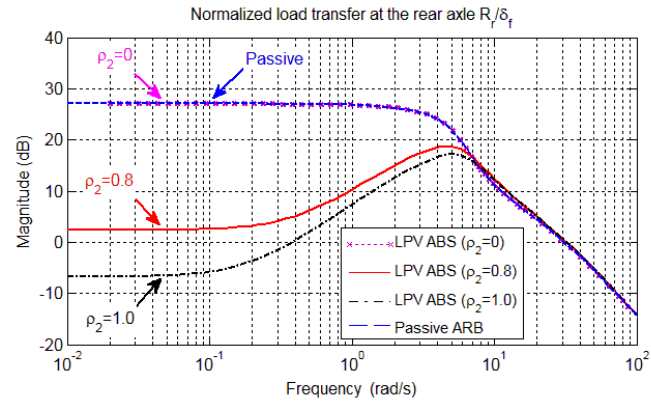

Figure 6. $2^{\text {nd }}$ case: transfer function magnitude of

(a) the lateral acceleration $\frac{a_{y}}{\delta_{f}}$, (b) the yaw moment $\frac{M_{Z}}{\delta_{f}},(c, d)$ the normalized load transfers

$$
\frac{R_{f, r}}{\delta_{f}} \text { at the two axles }
$$

The objective of the $\mathrm{H}_{\propto} / \mathrm{LPV}$ active braking control design is to prevent the vehicle rollover in an emergency situation with the considered frequency range to over $4 \mathrm{rad} / \mathrm{s}$. Figure 5 shows the transfer function magnitude of (a) the lateral acceleration, (b) the yaw moment, and (c, d) the normalized load transfers at the two axles. We can see that the $\mathrm{H}_{\infty} / \mathrm{LPV}$ active braking control system reduces significantly the lateral acceleration and the normalized load transfers in the specified frequency range. By penalizing the lateral acceleration, the lateral tyre forces are reduced, therefore the normalized load transfers are also reduced.

5.2. $2^{\text {nd }}$ case: the varying parameters $\rho_{2}=[0$, $0.8,1]$ varies and $\rho_{I}=v=80 \mathrm{~km} / \mathrm{h}$

In this case, the forward velocity is kept constant at $\rho_{1}=v=80 \mathrm{~km} / \mathrm{h}$, while the varying parameter $\rho_{2}$ is surveyed at the three values: $\rho_{2}=0, \rho_{2}=0.8, \rho_{2}=1.0$. Figure 6 shows the simulation results in the frequency domain of the lateral acceleration, the yaw moment, as well as the normalized load transfers at the two axles. They show clearly the effect of the varying parameter $\rho_{2}$ to prevent vehicle rollover in the frequency range to over $4 \mathrm{rad} / \mathrm{s}$. When the varying parameter $\rho_{2}$ increases, the lateral acceleration and the normalized load transfers at the two axles decrease, which means that the active braking system can adapt to the rollover situation by increasing $\rho_{2}$. The reduction of the transfer function magnitude of the lateral acceleration and of the normalized load transfers when $\rho_{2}=[0,0.8,1]$, compared to the passive anti-roll bar system, is summarized in Table 2.

Table 2. Reduction of the magnitude of the transfer functions compared to the passive antiroll bar system

\begin{tabular}{cccc}
\hline Transfer functions & $\boldsymbol{\rho}_{2}=\mathbf{0}$ & $\boldsymbol{\rho}_{2}=0.8$ & $\boldsymbol{\rho}_{2}=\mathbf{1}$ \\
\hline$\frac{a_{y}}{\delta_{f}}$ & 0 & $16 \mathrm{~dB}$ & $18 \mathrm{~dB}$ \\
$\frac{R_{f}}{\delta_{f}}$ & 0 & $9 \mathrm{~dB}$ & $10 \mathrm{~dB}$ \\
$\frac{R_{r}}{\delta_{f}}$ & 0 & $25 \mathrm{~dB}$ & $34 \mathrm{~dB}$ \\
\hline
\end{tabular}


These simulation results indicated that the reductions of the normalized load transfers at the two axles are about $40 \%$ by using the active braking system. Moreover, with the two varying parameters, the controller can adapt to the vehicle rollover phenomenon in emergencies.

\section{Conclusions}

This paper proposes the first preliminary results on the combination of the active braking system and the passive anti-roll bar system for a truck. The grid-based LPV approach is used to synthesize the $\mathrm{H}_{\circ} / \mathrm{LPV}$ active braking controller, which is selfscheduled by two varying parameters. The parameter dependent weighting function for the lateral acceleration is used in order to allow for the vehicle performance adaptation to the risk of rollover. The simulation results in the frequency domain emphasize the efficiency of the proposed methodology.

In normal situations, the active braking system is in "off" mode, but when the normalized load transfer at the rear axle reaches its limit, the active braking system will be activated, thus improving the vehicle behaviour. Hence, in the future, a braking monitor will be needed in order that the $\mathrm{H}_{\propto} / \mathrm{LPV}$ active braking control system will satisfy simultaneously the two objectives, which are the prevention of vehicle rollover and the increased stability at the smooth switching points.

\section{Acknowledgement}

This work has been supported by the University of Transport and Communications through the key project T2019-CK-012TD.

\section{REFERENCES}

[1]. G. Leen, and H. Donal, "Expanding Automotive Electronic Systems," Computer, vol. 35, no. 1, pp. 88-93, 2002.

[2]. D'alfio N., A. Morgando, and A. Sorniotti, "Electro-hydraulic brake systems: design and test through hardware-in-the-loop simulation," Vehicle System Dynamics: International Journal of Vehicle Mechanics and Mobility, vol. 44, pp. 378-392, 2006.

[3]. B. Caglar, E. Kose, and G. Anla, "Robust control of anti-lock brake system," Vehicle System Dynamics: International Journal of Vehicle Mechanics and Mobility, vol. 45, no. 3, pp. 217-232, 2007.

[4]. S. Savaresi, and T. Mara, Active Braking Control Systems Design for Vehicles. Springer, 2010.

[5]. P. Laszlo, A. Semsey, and E. Gerum, "RollOver Prevention System for Commercial Vehicles - Additional Sensorless Function of the Electronic Brake System," Vehicle System Dynamics: International Journal of Vehicle Mechanics and Mobility, vol. 32, no. 4-5, pp. 285-297, 1999.

[6]. G. Morrison, and D. Cebon, "Combined emergency braking and turning of articulated heavy vehicles," Vehicle System Dynamics: International Journal of Vehicle Mechanics and Mobility, vol. 55, no. 5, pp. 725-749, 2017.

[7]. V. T. Vu, O. Sename, L. Dugard, and P. Gaspar, "Enhancing roll stability of heavy vehicle by LQR active anti-roll bar control using electronic servovalve hydraulic actuators," Vehicle System Dynamics: International Journal of Vehicle Mechanics and Mobility, vol. 55, no. 9, pp. 1405-1429, 2017.

[8]. G. Peter, J. Bokor, and I. Szaszi, "The Design of a Combined Control Structure to Prevent the Rollover of Heavy Vehicles," European Journal of Control, vol. 10, no. 2, pp. 148162, 2004.

[9]. G. Peter, J. Bokor, and I. Szaszi, "Reconfigurable control structure to prevent the rollover of heavy vehicles," Control Engineering Practice, vol. 13, no. 6, pp. 699$711,2005$.

[10]. V. T. Van, "Enhancing the roll stability of heavy vehicles by using an active anti-roll bar system," $\mathrm{PhD}$ thesis, University Grenoble Alpes, 2017.

[11]. S. David, and D. Cebon, "Active Roll Control of Single Unit Heavy Road Vehicles," Vehicle System Dynamics: International Journal of Vehicle Mechanics and Mobility, vol. 40, no. 4, pp. 229-270, 2003.

[12]. H. Arnar, P. Seiler, and A. Packard, "LPVTools: A Toolbox for Modeling, Analysis, and Synthesis of Parameter Varying Control Systems," First IFAC Workshop on Linear Parameter Varying Systems, France, 2015. 
[13]. M. Andres, and G. J. Balas, "Development of Linear-Parameter-Varying Models for Aircraft," Journal of Guidance, Control, and Dynamics, vol. 27, no. 2, pp. 218-228, 2004.

[14]. H. Simon, "Generating structured LPVmodels with maximized validity region," IFAC World Congress - $19^{\text {th }}$ IFAC WC 2014, Cape Town, South Africa, 2014.
[15]. H. Arnar, P. Seiler, and G. J. Balas, "LPV aeroservoelastic control using the LPVTools toolbox," AIAA Atmospheric Flight Mechanics, United States, 2013.

[16]. V. T. Vu, O. Sename, L. Dugard, and P. Gaspar, "Ho/LPV controller design for an active anti-roll bar system of heavy vehicles using parameter dependent weighting functions," Heliyon, vol. 5, no. 6, pp. 1-11, 2019. 